\title{
Effect of crystallinity on CF/PPS performance under weather exposure: Moisture, salt fog and UV radiation
}

\author{
Natassia L. Batista ${ }^{a, b},{ }^{*}$, Mirabel C. Rezende ${ }^{c}$, Edson C. Botelho ${ }^{b}$ \\ a Department of Mechanical Engineering, McGill University, 817 Sherbrook Street West, Montreal, QC H3A 0C3, Canada \\ b Department of Materials and Technology, UNESP, Av. Ariberto Pereira da Cunha, 333, Guaratingueta, SP, Brazil \\ ${ }^{\mathrm{c}}$ Institute of Science and Technology, UNIFESP, R. Talim, 330, Sao Jose dos Campos, SP, Brazil
}

\section{A R T I C L E I N F O}

\section{Article history:}

Received 10 October 2017

Received in revised form 30 January 2018

Accepted 11 March 2018

Available online 12 March 2018

\section{Keywords:}

Carbon fibers

Polymers

Environmental degradation

Crystallinity

\begin{abstract}
A B S T R A C T
The crystalline content of a composite can affect its performance under environmental conditions. The objective of this study is to evaluate the influence of the crystallinity degree of CF/PPS composites to hygrothermal, salt fog and ultraviolet/condensation conditioning. DSC and DMA results, and Young's modulus and ILSS values were used to evaluate the changes in the thermal and mechanical properties of $\mathrm{CF} / \mathrm{PPS}$ composites after conditioning. The crystallinity degree showed to affect the water uptake and the severity of degradation. Differences up to $40 \%$ were found among the mechanical properties values depending on the crystallinity. In the hygrothermal and salt fog conditioning the least crystalline laminates were mostly degraded. In contrast, in the ultraviolet/condensation conditioning the composites with the highest crystalline contents were more affected.
\end{abstract}

() 2018 Published by Elsevier Ltd.

\section{Introduction}

Polyphenylene sulfide (PPS) is a high performance thermoplastic that is getting increasing attention in aerospace applications $[1,2]$. This polymer can attain a high crystallinity degree $(\sim 60 \%)$ and has excellent mechanical properties, i.e. high modulus and tensile strength [1,3]. Due to its high crystallinity and aromatic structure, the mechanical properties are retained up to $200^{\circ} \mathrm{C}$ [1]. Moreover, PPS is chemically inert and not affected by aircraft fluids [3]. In addition to being applied in aircraft interiors, CF/PPS is also used in aircraft structural applications, such as in J-Nose wing substructures of the Airbus A340-500/600 [4].

High performance thermoplastic composites can be obtained by different processing techniques, namely powder processing, film stacking, and semi-preg consolidation [1]. During the molding cycle, the cooling rate will influence the way in which the polymer chains are organized to form the crystalline arrangement. The final degree of crystallization and the morphology of the crystals will have a direct influence on the mechanical properties and on the environmental performance of the composite $[1,3]$.

The performance of thermoplastic composite materials under

\footnotetext{
* Corresponding author. Department of Mechanical Engineering, McGill University, 817 Sherbrook Street West, Montreal, QC H3A 0C3, Canada.

E-mail address: natassia.lonabatista@mail.mcgill.ca (N.L. Batista).
}

prolonged exposure to high humidity and salinity is usually superior when compared with traditional materials [5]. Nevertheless, their performance after long-term exposure to environmental conditions such as moisture, salinity and ultraviolet (UV) radiation needs to be well understood in order to prevent unexpected failures $[1,5,6]$.

Hygrothermal exposure can cause a variety of reversible and irreversible changes in the polymer matrix $[7,8]$. The carbon fiber (CF) does not absorb moisture, but the fiber-matrix interface can act as a preferential pathway for moisture ingression [9]. Moisture is introduced to the composite via water diffusion through the matrix and fiber-matrix interfaces, and water uptake by microcracks and microvoids [10-12]. The reversible changes that can be caused include plasticization and swelling of the matrix, whereas the irreversible include microcracking, debonding of the fiber from the matrix, hydrolysis of the polymer chains and leaching of matter from the composite [13-16]. In addition, the degradation due to moisture exposure is usually accelerated at elevated temperature $[10,13]$. Mechanical tests such as interlaminar shear strength (ILSS) are often used after hygrothermal exposure for being strongly correlated to fiber-matrix adhesion strength $[10,12]$.

A few studies have been performed on PPS hygrothermal exposure. Papanicolaou et al. [17] conditioned PPS reinforced with short glass fibers (GF) for $2000 \mathrm{~h}$ in hot water immersion at $140{ }^{\circ} \mathrm{C}$ and observed a $1.1 \%$ weight increase. Kawaguchi et al. [18] carried 
out a conditioning by hot water immersion at $90^{\circ} \mathrm{C}$ on GF/PPS for one year. The weight increased approximately $0.5 \%$ and the tensile resistance dropped by $57 \%$, which was assigned to the degradation of the fiber-matrix interface. Moreover, a study on CF/PPS kept for 3 months at $70^{\circ} \mathrm{C}$ in relative humidity of $85 \%$ was performed by Blond et al. [3]. The authors verified a weight increment of $0.08 \%$ in the composite and a crystalline fraction increase, which was reported as unexpected.

Saline solution $(\mathrm{NaCl})$ induces similar irreversible changes as distilled water to polymer composites, such as hydrolysis and leaching of low molecular weight molecules [13]. However, some controversy is found in the literature regarding which conditioning can be more aggressive. Mouzakis et al. [13] states that salt crystals can inhibit the diffusion of water, by blocking the paths through which water diffuses into the material, resulting in greater extent absorption of distilled water compared to salted water. In addition, Deroiné et al. [19] concludes that degradation rate is faster in distilled water than in seawater due to the lack of mineral salts, which facilitates the diffusion of water within the polymer. In contrast, Karbhari and Ghosh [20] study found saltwater to be more deteriorating to bond strength than deionized water. Moreover, $\mathrm{Hu}$ et al. [7] results show a greater moisture uptake in salt water compared to deionized water.

Studies on PPS exposure to salty water have been carried out previously. Davies et al. [21] evaluated GF/PPS after immersion in sea water. An increment of $0.2 \%$ in the weight was found, as well as a drop of $65 \%$ in the Young's modulus and $85 \%$ in the tensile strength at break, as a result of the fiber-matrix interface degradation. Pomiès et al. [22] conditioned GF/PPS samples in sea water at $35^{\circ} \mathrm{C}$ for 7 months. An increase of approximately $0.15 \%$ in the weight was observed and a substantial reduction of $89 \%$ in the Young's modulus was obtained due to fiber-matrix interface debonding caused by water absorption. In addition, Costa et al. [23] evaluated the CF/PPS performance after 30 days in artificial sea water immersion at room temperature and also after 8 weeks in hot water immersion at $80^{\circ} \mathrm{C}$, for comparison. An increment of $0.10 \%$ and $0.35 \%$ in the weight was verified for the samples conditioned in saline solution and hot water, respectively. A reduction of $14 \%$ in the interlaminar shear strength (ILSS) after hygrothermal conditioning and of $3 \%$ after saline conditioning was also observed due to a possible degradation in the fiber-matrix interface.

The UV radiation that reaches the earth has a wavelength between 280 and $400 \mathrm{~nm}$, divided in: UV-A, with wavelength between 320 and $400 \mathrm{~nm}$; and UV-B, between 280 and $320 \mathrm{~nm}$ $[24,25]$. As the energy generated by these wavelengths is approximately the same as the energy of the covalent bonds, it can modify the polymer chemical structure, leading to photo-oxidation, chain scission and cross-linking [1,24,26,27]. As a result, yellowing and loss of mechanical properties are commonly verified $[28,29]$. In addition, sulphur dioxide also causes cross-linking, which accelerates the PPS degradation [30]. Chain cross-liking is known to reduce molecular mobility and may lead to excessive brittleness of the polymer, which is mainly responsible for the formation of microcracks [1,29]. Consequently, microcracks provide pathways for faster water uptake [30]. Water condensation and UV can act synergistically, as the microcracks formed by UV degradation accelerates the water absorption and swelling, leading to new and deeper cracks and allowing UV to cause further damage [26,30]. However, UV radiation can also be beneficial by increasing the local crystallinity and as a result the material modulus [28].

Some previous investigations on the GF/PPS behavior after UV/ condensation exposure are found. De Faria et al. [31] observed color variation and cracking of the surface after $1900 \mathrm{~h}$ of UV exposure. Costa et al. [32] verified not only color variation and cracking of the surface, but also a $3 \%$ reduction in the ILSS after $900 \mathrm{~h}$ of UV/ condensation conditioning. Sinmazçelik et al. [30], after $2211 \mathrm{~h}$ of UV conditioning, verified a drop of $1.6 \%$ in the Charpy impact resistance and of $1.5 \%$ in the Young's modulus. After $3216 \mathrm{~h}$, the photodegrading intensified, resulting in a decrease of $8.3 \%$ in the impact resistance and $10.8 \%$ in the Young's modulus. In addition, a reduction of $1.1 \%$ in the weight was also observed for the longest period of UV exposure. A study on CF/PPS was also conducted by Mahat et al. [1], where a $21 \%$ increase in the tensile strength was verified after $240 \mathrm{~h}$ of UV conditioning with a subsequent decreasing of the values in the following hours until $480 \mathrm{~h}$.

Although the effect of weathering on PPS has been fairly studied in the literature, there are still limited studies on CF/PPS composites, some controversial results and poor understanding on the influence of the crystallinity degree. In this work, the main purpose was to evaluate the environmental performance to moisture, salinity and UV/condensation of CF/PPS composites obtained with different crystallinity degrees. The Young's modulus and the ILSS were determined to assess the degradation on the mechanical properties. Thermal characterization was also carried out by DSC and DMA, as well as stereoscopy of the conditioned samples.

\section{Material and methods}

\subsection{Material and processing}

PPS films (thickness $0.125 \mathrm{~mm}$, density $1.35 \mathrm{~g} / \mathrm{cm}^{3}$, melting point $285^{\circ} \mathrm{C}$ ) were supplied by Curbell Plastics and plain weave carbon fiber fabrics (AS4GP $3 \mathrm{~K}$, area weight $193 \mathrm{~g} / \mathrm{m}^{2}$ ) by Hexcel. Laminates were manufactured with a reinforcement/matrix volume fraction of $60 / 40(\mathrm{v} / \mathrm{v})$ by stacking alternatively layers of PPS films and carbon fabric in a stainless steel mold. A total of 15 carbon fiber plies were used to obtain $300 \mathrm{~mm} \times 300 \mathrm{~mm} \times 2.5 \mathrm{~mm}$ composites by compression molding.

In the processing cycle, the material was heated up at approximately $10^{\circ} \mathrm{C} . \mathrm{min}^{-1}$ from room temperature up to $315^{\circ} \mathrm{C}$, held in this temperature for $30 \mathrm{~min}$ under a pressure of $1.2 \mathrm{MPa}$ and then cooled down to room temperature. In order to vary the final crystallinity degree different cooling rates were performed: 1 ) fast rate of approximately $10^{\circ} \mathrm{C} . \mathrm{min}^{-1} ; 2$ ) slow rate of about $1^{\circ} \mathrm{C} . \mathrm{min}^{-1}$ and; 3) air cooling, obtained by leaving the press, die and laminate cool naturally in air (the rate decays from 1 to $0.1^{\circ} \mathrm{C} \cdot \mathrm{min}^{-1}$ as the system cools down).

\subsection{Environmental conditioning}

Before conditioning, all specimens were dried in an oven at $60{ }^{\circ} \mathrm{C}$ until constant weight was approached. Three control samples (traveler samples) of dimensions $50 \mathrm{~mm} \times 14 \mathrm{~mm} \times 2.5 \mathrm{~mm}$ were used in each climate chamber to monitor weight change throughout the different conditionings performed: hygrothermal, salt fog and ultraviolet/condensation. Prior each periodical weighing, the samples were dried with paper towel to remove residual surface water.

The hygrothermal conditioning was carried out in a controlled Marconi climatic chamber model MA835/UR in accordance to ASTM D 5229/D 5229 M 04. The specimens were exposed to $90 \%$ relative humidity at $80^{\circ} \mathrm{C}$ for a period of eight weeks.

The salt fog conditioning was performed in an Equilam salt spray chamber in accordance to ASTM B117-11 standard. The specimens were exposed to a direct spray of a 5\%-by-mass aqueous solution of $\mathrm{NaCl}$ at $35^{\circ} \mathrm{C}$ during three weeks.

The ultraviolet/condensation conditioning was carried out in an accelerated weathering tester model QUV/spray with solar eye irradiance control, according to ASTM G 154. The damages caused by UV radiation and dew were reproduced by alternate cycles of 
$8 \mathrm{~h}$ at $60^{\circ} \mathrm{C}$ under $\mathrm{UV}$ and $4 \mathrm{~h}$ at $50^{\circ} \mathrm{C}$ under water condensation. UV exposure was made with $340 \mathrm{~nm}$ wavelength UV-A light set at $0.76 \mathrm{~W} / \mathrm{m}^{2}$ intensity. The specimens were subjected to the UV/ condensation conditioning for $900 \mathrm{~h}$.

\subsection{Composite characterization}

The influence of the crystallinity degree on the CF/PPS weather resistance was evaluated by differential scanning calorimetry (DSC), dynamic mechanical analysis (DMA), interlaminar shear strength (ILSS) and impulse excitation technique (to determine the Young's modulus).

DSC experiments were performed on Seiko Exstar 6000 - DSC 6220 differential scanning calorimeter, operating under nitrogen flow at a heating rate of $10^{\circ} \mathrm{C} \cdot \mathrm{min}^{-1}$. Composite samples of approximately $2 \times 2 \times 2.5 \mathrm{~mm}$ were extracted from three different parts of the plate for each condition. The degree of crystallinity was calculated using the following Eq. (1):

$X_{c}(\%)=\frac{\Delta H_{c}}{\Delta H_{m}^{\circ}(1-x)} \times 100 \%$

where: $\mathrm{Xc}, \Delta \mathrm{Hc}, \Delta \mathrm{H}^{\circ} \mathrm{m}$ and $\mathrm{x}$ are respectively the degree of crystallinity, the enthalpy obtained by the melting peak area, the melting enthalpy of PPS $100 \%$ crystalline $(80 \mathrm{~J} / \mathrm{g})$ [33] and the weight fraction of the fibers. Note that the result obtained is an approximation using small samples, which might not be representative of the entire composite.

DMA was carried out using rectangular specimens of dimensions $50 \mathrm{~mm} \times 14 \mathrm{~mm} \times 2.5 \mathrm{~mm}$. The storage modulus $\left(\mathrm{E}^{\prime}\right)$, loss modulus $\left(\mathrm{E}^{\prime \prime}\right)$ and loss factor $(\tan \delta)$ of the specimens were measured as a function of temperature $\left(30-170^{\circ} \mathrm{C}\right)$ under dual cantilever mode using a Seiko Exstar 6000 - DMS 6100, at frequency of $1 \mathrm{~Hz}$, amplitude of $10 \mu \mathrm{m}$ and heating rate of $3^{\circ} \mathrm{C} \cdot \mathrm{min}^{-1}$. The glass transition temperature $\left(T_{g}\right)$ was obtained from the $E^{\prime}$ onset as it gives the most conservative value.

ILSS tests were performed using a Shimadzu autograph AG-X series precision universal machine at room temperature, constant cross-speed of $1 \mathrm{~mm} \mathrm{~min}^{-1}$ and a load cell of $5 \mathrm{kN}$, in accordance to ASTM D2344. The dimensions of the specimens were $15 \mathrm{~mm} \times 5.5 \mathrm{~mm} \times 2.5 \mathrm{~mm}$.

Impulse excitation technique was employed to determine the Young's modulus by using the composites natural frequency. In this technique, a rectangular specimen under flexure mode is lightly stroked and the acoustic response captured is used to calculate the Young's modulus. The impulse excitation technique was performed in accordance to ASTM 1876 using Sonelastic ${ }^{\circledR}$ equipment developed by ATCP - Physical Engineering (Brazil). Specimens of dimensions $50 \mathrm{~mm} \times 14 \mathrm{~mm} \times 2.5 \mathrm{~mm}$ were used. As plain weave fabrics should lead to almost isotropic materials, there should be no significant effect of the orientation when properties are measured.

Stereoscopy was performed using a Zeiss Stemi 2000 stereoscope in order to investigate possible changes on the samples surfaces after environmental conditioning.

\section{Results and discussion}

The crystallinity degrees of conditioned $\mathrm{CF} / \mathrm{PPS}$ specimens are given in Table 1. The effect of hygrothermal and ultraviolet/ condensation conditionings on the crystallinity degree appears to be more significant for the composites obtained by fast cooling. As far as the hygrothermal conditioning is concerned, the high temperature inside the chamber and the water ingress into the samples resulted in a considerable increment $(\sim 17 \%)$ in crystallinity, which was probably caused by movement gain and reordering of the
Table 1

Conditioning effect on the crystallinity of the CF/PPS composites obtained by different cooling rates.

\begin{tabular}{llll}
\hline & \multicolumn{2}{l}{ \% Crystallinity } & \\
\cline { 2 - 4 } & Fast & Slow & In air \\
\hline Not conditioned & $51 \pm 1$ & $59 \pm 1$ & $62 \pm 2$ \\
Hygrothermal & $60 \pm 2$ & $61 \pm 2$ & $62 \pm 1$ \\
Salt fog & $52 \pm 1$ & $58 \pm 1$ & $60 \pm 1$ \\
UV/condensation & $57 \pm 1$ & $57 \pm 1$ & $58 \pm 3$ \\
\hline
\end{tabular}

polymer chains. On the other hand, crystalline increase ( $12 \%)$ after UV/condensation conditioning was mostly likely due to a process called chemi-crystallization, where part of the polymer chains in the amorphous region are broken by UV radiation, giving them enough mobility to form new crystals [34].

It is worth mentioning that DSC isotherms at $80^{\circ} \mathrm{C}$ of the conditioned samples were also performed for $1 \mathrm{~h}$ in order to discard de possibility that the increase in crystallinity was a result of cold crystallization. In addition, note that a previous study on the crystal morphology of CF/PPS was performed using polarized light optical microscopy [35]. In that study, the crystals showed to grow in a homogenous manner, even for the slowest cooling rate $\left(0.5^{\circ} \mathrm{C} /\right.$ min). Small crystallites were always observed for all the cooling rates, unlike to what is usually observed for polymers such as PEEK, for example. Hence, the authors believe that information on CF/PPS crystals morphology would not have a significant contribution in the present work.

The average weight gain (\%) of $\mathrm{CF} / \mathrm{PPS}$ specimens exposed to hygrothermal conditioning is plotted vs. $\sqrt{t}$ in Fig. 1(a). The moisture uptakes of all samples increase abruptly and then rapidly stabilize reaching the moisture saturation level in approximately 12 days $\left(\sim 17 \mathrm{~h}^{1 / 2}\right)$. Moisture absorption content is not found to vary significantly throughout the hygrothermal conditioning. The final weight gain was of $0.09 \%$, which is in agreement with a similar study conducted by Blond et al. [3], where a $0.08 \%$ weight gain was found. If the water uptake obtained for each crystallinity degree is compared, a difference of $0.02 \%$ is observed between the samples with the lowest crystallinity (fast) from the others, indicating that the crystalline structure acts as a barrier to the moisture ingress.

The storage modulus $\left(\mathrm{E}^{\prime}\right)$, loss modulus $\left(\mathrm{E}^{\prime \prime}\right), \tan \delta$ and glass transition temperature $\left(\mathrm{T}_{\mathrm{g}}\right)$ of $\mathrm{CF} / \mathrm{PPS}$ composites after hygrothermal conditioning are shown in Table 2. As it can be seen from these results, the storage moduli are considerably higher after hygrothermal conditioning, especially for the laminates obtained by fast cooling $(\sim 14 \%)$. This may be attributable to the crystallinity increase verified by DSC experiments, as a result of the samples exposure to high temperature $\left(80^{\circ} \mathrm{C}\right)$ and high humidity $(90 \%)$.

The specimens were also tested by impulse excitation technique in order to calculate their Young's modulus and by ILSS tests, as shown in Table 3 and Table 4, respectively. Although a slight increase on Young's modulus and ILSS values was verified after hygrothermal conditioning, it was not significant considering the standard deviation. Common plasticization effects such as decrease of the glass transition temperature and Young's modulus [7] were not observed after hygrothermal conditioning, as showed in Tables 2 and 3 respectively.

Overall, the results obtained after hygrothermal didn't reveal a reduction of the mechanical properties in contradiction with Kawaguchi et al. [18] reports. However, the crystalline fraction increase described by Blond et al. [3] was also observed.

Fig. 1(b) depicts the average weight gain (\%) of CF/PPS specimens exposed to salt fog conditioning plotted vs. time. The final weight gain observed of $0.4 \%$ is remarkably superior when compared to the one obtained by hygrothermal conditioning (0.09\%). This behavior 


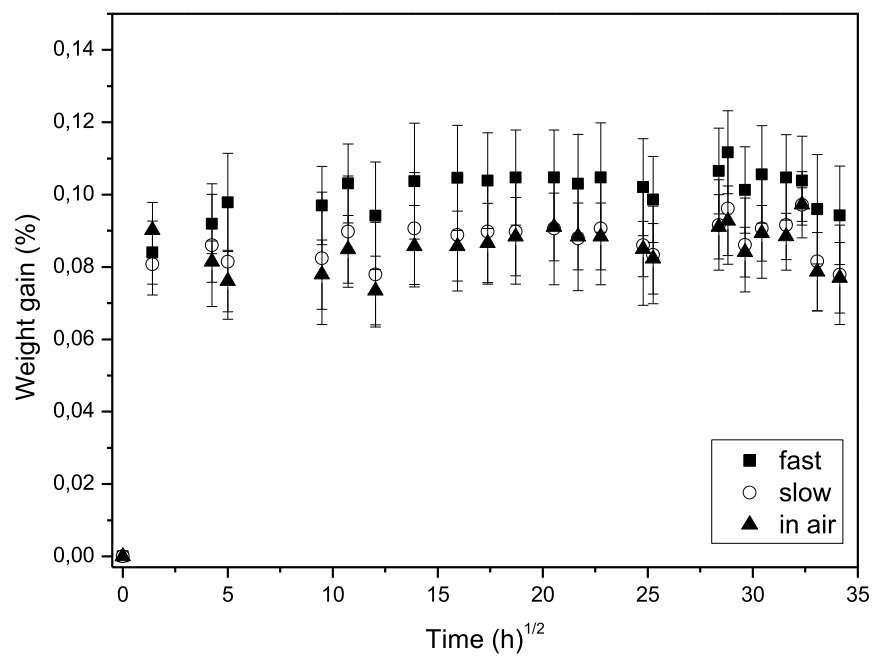

(a)

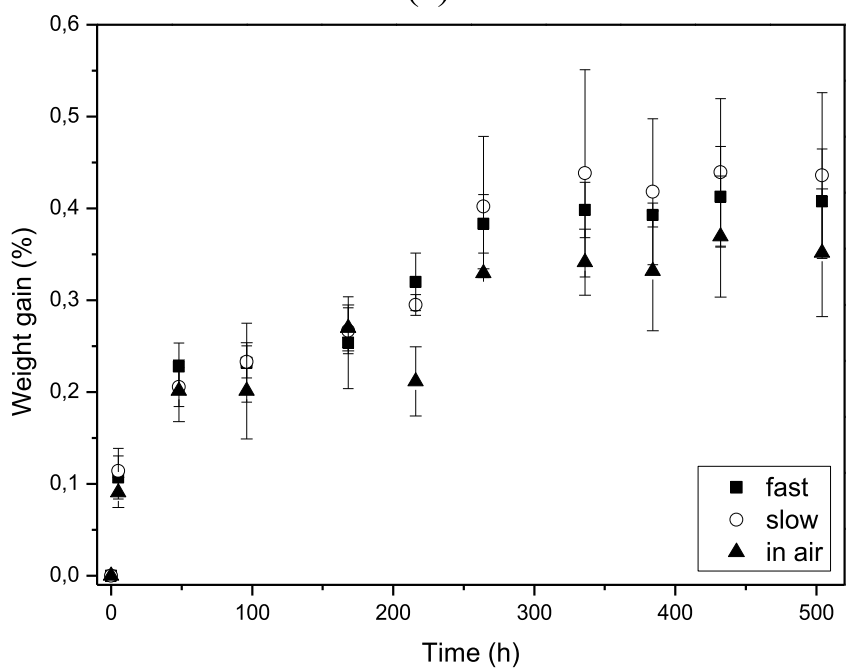

(b)

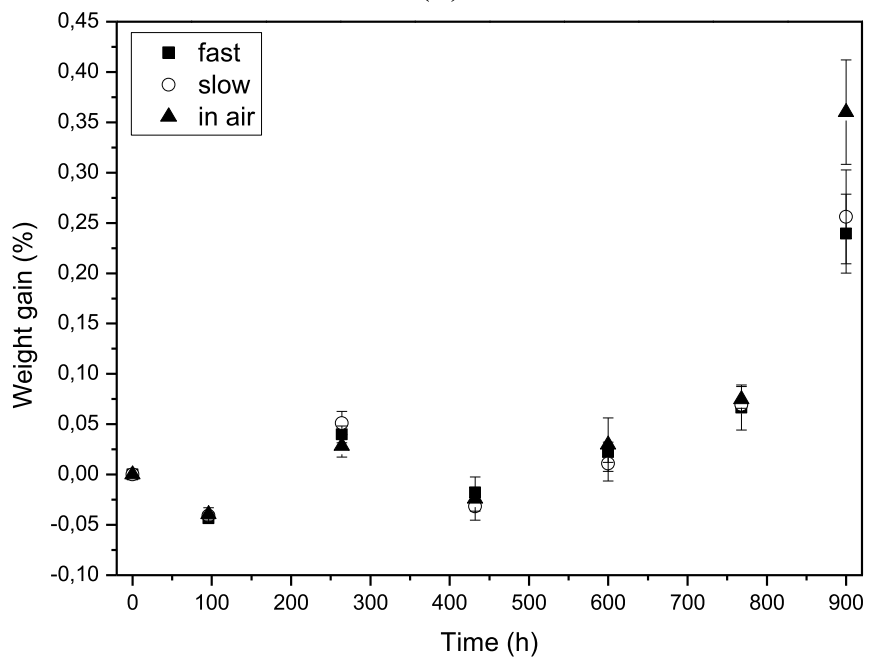

(c)

Fig. 1. Weight variation of CF/PPS composites during: (a) hygrothermal, (b) salt fog and (c) UV/condensation conditioning.

contradicts Mouzakis et al. [13] and Deroiné et al. [19] which state that salt crystals could inhibit the diffusion of water, but is in
Table 2

DMA results after hygrothermal, salt fog and ultraviolet/condensation conditioning of CF/PPS laminates obtained by different cooling rates.

\begin{tabular}{llllll}
\hline & & $E^{\prime}(\mathrm{GPa})$ & $\mathrm{E}^{\prime \prime}(\mathrm{GPa})$ & $\tan \delta$ & $\operatorname{Tg}\left({ }^{\circ} \mathrm{C}\right)$ \\
\hline \multirow{2}{*}{ Fast } & Not conditioned & $5.7 \pm 0.2$ & $0.23 \pm 0.02$ & $0.044 \pm 0.002$ & $87 \pm 1$ \\
& Hygrothermal & $6.5 \pm 0.3$ & $0.25 \pm 0.03$ & $0.040 \pm 0.001$ & $89 \pm 1$ \\
& Salt fog & $4.9 \pm 0.2$ & $0.23 \pm 0.01$ & $0.052 \pm 0.003$ & $83 \pm 2$ \\
& UV/condensation & $6.8 \pm 0.3$ & $0.23 \pm 0.02$ & $0.039 \pm 0.004$ & $81 \pm 1$ \\
\hline Slow & Not conditioned & $5.8 \pm 0.3$ & $0.20 \pm 0.02$ & $0.037 \pm 0.003$ & $86 \pm 1$ \\
& Hygrothermal & $6.2 \pm 0.4$ & $0.24 \pm 0.02$ & $0.042 \pm 0.003$ & $85 \pm 1$ \\
& Salt fog & $5.2 \pm 0.4$ & $0.22 \pm 0.03$ & $0.047 \pm 0.001$ & $84 \pm 1$ \\
& UV/condensation & $6.6 \pm 0.5$ & $0.22 \pm 0.02$ & $0.037 \pm 0.003$ & $81 \pm 2$ \\
\hline In air & Not conditioned & $6.1 \pm 0.4$ & $0.20 \pm 0.02$ & $0.035 \pm 0.002$ & $86 \pm 1$ \\
& Hygrothermal & $6.8 \pm 0.3$ & $0.20 \pm 0.02$ & $0.031 \pm 0.003$ & $84 \pm 2$ \\
& Salt fog & $6.0 \pm 0.5$ & $0.25 \pm 0.03$ & $0.038 \pm 0.002$ & $84 \pm 2$ \\
& UV/condensation & $6.6 \pm 0.7$ & $0.23 \pm 0.03$ & $0.038 \pm 0.002$ & $82 \pm 2$ \\
\hline
\end{tabular}

Table 3

Conditioning effect on the Young's modulus obtained by acoustic vibration damping.

\begin{tabular}{llll}
\hline & E (GPa) & & \\
\cline { 2 - 4 } & Fast & Slow & In air \\
\hline Not conditioned & $64 \pm 1$ & $67 \pm 1$ & $70 \pm 1$ \\
Hygrothermal & $66 \pm 1$ & $69 \pm 1$ & $73 \pm 2$ \\
Salt spray & $56 \pm 1$ & $60 \pm 2$ & $64 \pm 2$ \\
UV/condensation & $64 \pm 1$ & $64 \pm 1$ & $64 \pm 2$ \\
\hline
\end{tabular}

Table 4

Conditioning effect on the ILSS values.

\begin{tabular}{llll}
\hline & \multicolumn{2}{l}{ ILSS (MPa) } \\
\cline { 2 - 4 } & Fast & Slow & In air \\
\hline Not conditioned & $28 \pm 2$ & $28 \pm 3$ & $31 \pm 2$ \\
Hygrothermal & $32 \pm 3$ & $34 \pm 5$ & $35 \pm 2$ \\
Salt spray & - & - & - \\
UV/condensation & $23 \pm 2$ & $20 \pm 3$ & $19 \pm 4$ \\
\hline
\end{tabular}

agreement with Karbhari and Ghosh [20] and Hu et al. [7] finds. Although the weight gains of the laminates with different crystallinities don't present a significant deviation among them, at the second half of the conditioning the samples with higher crystalline content (in air) display lower weigh gain.

Unexpectedly, a few weeks after the salt fog conditioning, salt crystals started to form in the lateral of the specimens, as shown in Fig. 2. This phenomenon indicates that the $\mathrm{NaCl}$ probably migrated from the interior to the surface of the composite. The crystals arose mainly in the weft direction (showed by the ellipses), suggesting that is the $\mathrm{NaCl}$ preferential path. The quantity of salt showed to vary, where the samples with higher amorphous content displayed larger amounts of $\mathrm{NaCl}$ crystals. However, another major difference was identified, the presence of short fiber strands coming out of the sample mainly in the warp direction (indicated by the arrows). It is believed that those strands were displaced in the salt migration process to the surface.

The DMA results of CF/PPS composites after salt fog conditioning are shown in Table 2. A reduction in storage modulus is observed for the composites obtained by fast cooling ( $14 \%)$. In addition, increments in the $\tan \delta$ values were verified for the laminates processed by fast $(\sim 17 \%)$ and slow $(\sim 27 \%)$ cooling. Those variations were probably due to the saline solution ingress into the composite. The $\mathrm{NaCl}$ migration towards the lateral surface could also have contributed to the reduction of the storage modulus and the increase in the damping of the least crystalline samples.

As it can be seen in Table 3, the Young's moduli of the samples 


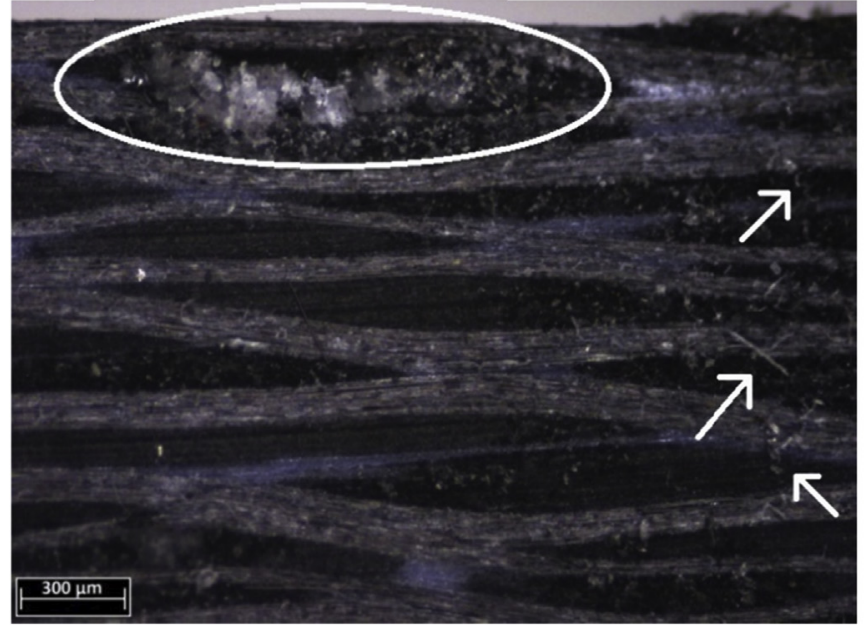

(a)

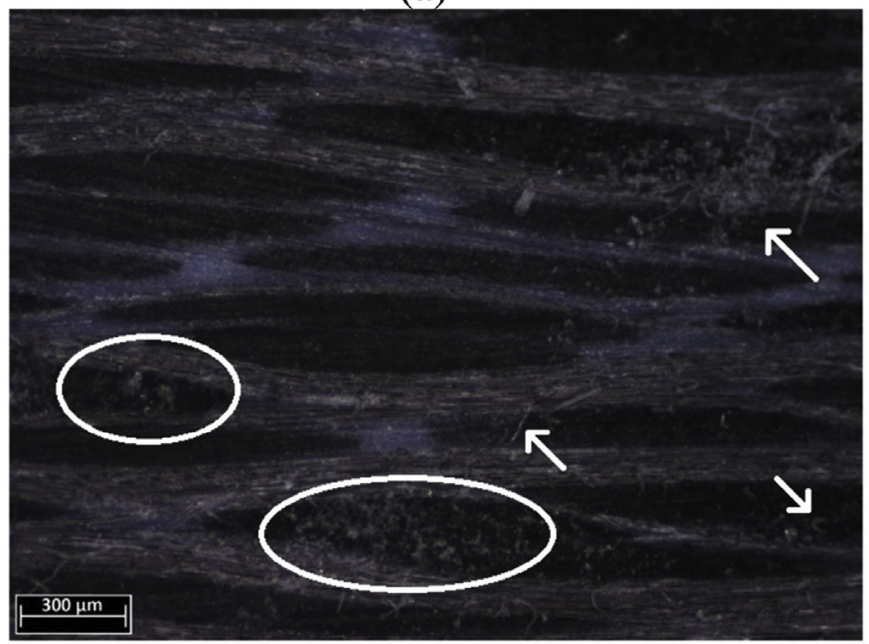

(b)

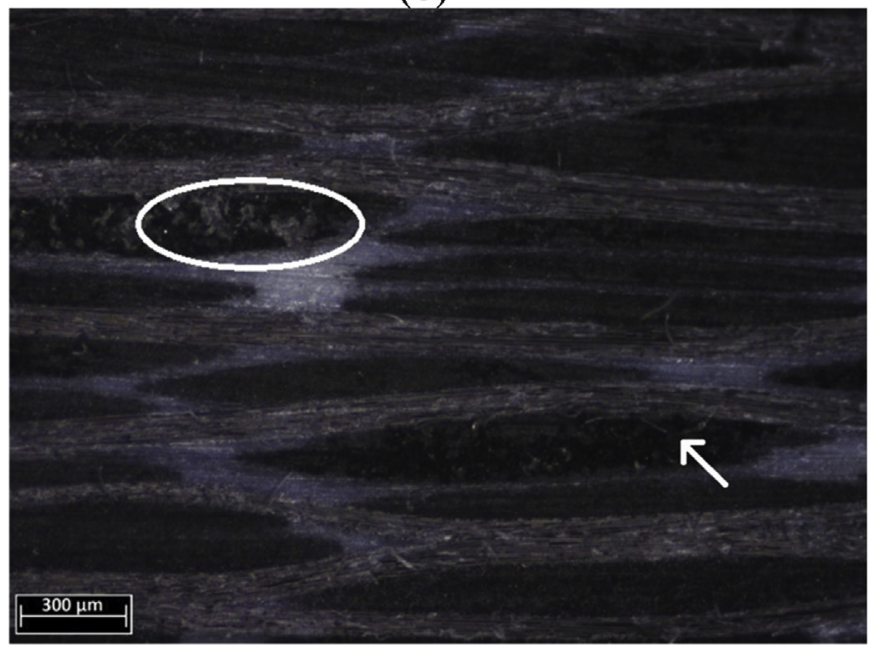

(c)

Fig. 2. Stereoscopy after salt fog conditioning of the lateral region of $\mathrm{CF} / \mathrm{PPS}$ laminates obtained by: (a) fast; (b) slow; and (c) in air cooling.

after the salt fog conditioning were reduced. However, the variation of the samples with lowest crystalline degree was more significant (up to $13 \%$ ). Thus, as for the DMA observations, this behavior is probably a result of the high weight gain due to the saline solution uptake and also the $\mathrm{NaCl}$ migration in the composite laminate.

No valid results were obtained for the ILSS tests (Table 4) performed after the salt fog conditioning since flexural deformation was being observed instead of shear. This alteration in the material response indicates that the salt fog conditioning degraded the composite fiber-matrix interface.

Previous studies also verified a drop in the Young's modulus [21,22] and ILSS [23] after exposing PPS composites to $\mathrm{NaCl}$ solution. The reduction in the mechanical performance was attributed to the degradation of the fiber-matrix interface [21,22].

The weight variation of CF/PPS specimens throughout the ultraviolet/condensation conditioning is shown in Fig. 1(c). An oscillation in the weight gain and loss is observed for the first $700 \mathrm{~h}$, probably due to the synergistically action between moisture and UV radiation $[26,30]$. The UV radiation would lead to cracks and the cracks to higher water absorption and further cracking. The high weight gain of approximately $0.3 \%$, when compared to the hygrothermal conditioning $(0.09 \%)$, indicates that the erosion caused by the UV degradation allowed more water ingress, resulting in greater weight gain. According with this study, the water uptake was more significant for the composites with higher degree of crystallinity, suggesting that they are more vulnerable to the UV radiation effects.

In order to further investigate the effect of UV/condensation conditioning on the composites surface, stereoscopy was used as shown in Fig. 3. A distinct change of color is seen due to the formation of chromophore groups that absorb visible wavelength. In addition, the erosion of the polymer was accelerated with the crystalline content increase. The sample with higher crystalline degree (Fig. 3(d)) showed to have the first woven layer almost completely exposed and the remainder polymer was highly photooxidized.

In order to better understand this phenomenon, an analogy of the visible light and $\mathrm{X}$-rays with the UV waves is proposed, which are all electromagnetic waves. When a ray of visible light strikes a semi-crystalline polymer, the crystalline regions diffract and scatter the ray making the polymer look opaque [36], whereas in an amorphous polymer the same ray would pass freely making it transparent. In fact, scattering is useful for assessing the structure of semi-crystalline polymers, in X-ray scattering techniques for example [36]. UV radiation has a wavelength range that is between the wavelengths of visible light and X-rays, and is also diffracted and scattered by the polymer crystallites [36]. Therefore, when the UV ray strikes a semi-crystalline polymer, it is diffracted and scattered, staying for a longer period of time "trapped" in the polymer structure and causing more harm. Consequently, the higher was the crystallinity degree of the PPS, more it was damaged by the UV rays.

Table 2 shows the storage modulus, loss modulus, $\tan \delta$ and glass transition temperature of $\mathrm{CF} / \mathrm{PPS}$ composites after UV/ condensation conditioning. An increase in the storage modulus of the composites obtained by fast cooling ( $19 \%)$ is observed probably due to the increment in the crystalline degree (Table 1) promoted by a process called chemi-crystallization, as mentioned previously. Moreover, it was verified a drop in the glass transition temperatures for all the samples $(\sim 4-6 \%)$ that probably resulted from photo-oxidation, by breakage of the covalent bonds in the crystalline regions.

The Young's moduli of the CF/PPS laminates after UV/condensation conditioning are shown in Table 3 . A reduction in the values is observed for the composites obtained by slow $(\sim 5 \%)$ and in air ( 9\%) cooling, indicating again that the composites with higher crystallinity degree were more degraded by the UV/condensation conditioning. The breakage of parts of the polymer chain and following erosion of the surfaces was probably the cause of this drop. 


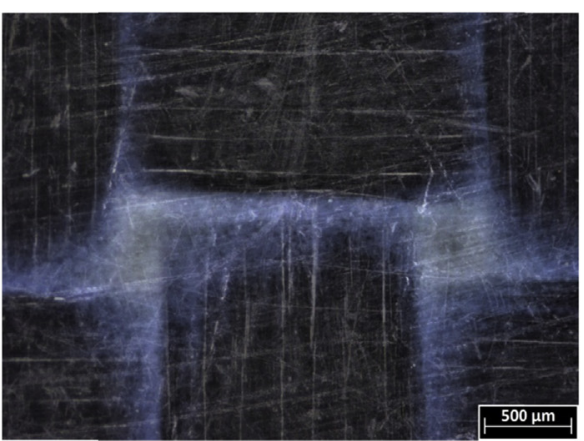

(a)

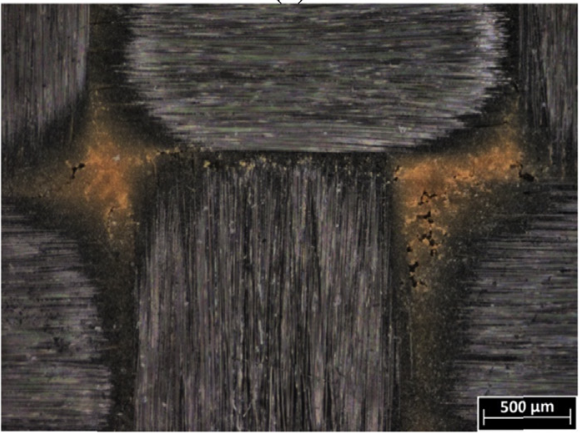

(c)

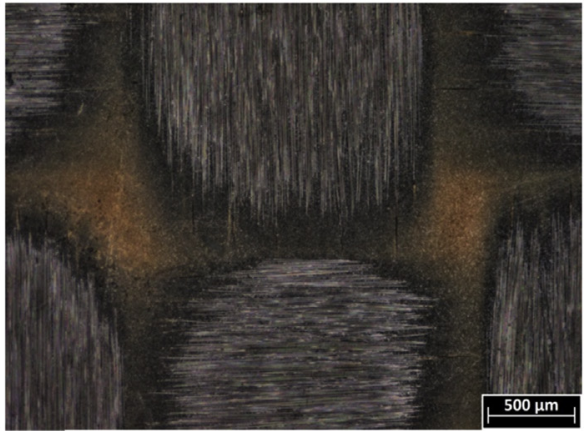

(b)

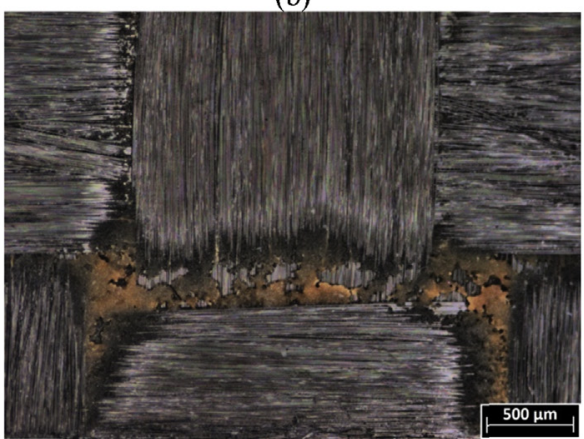

(d)

Fig. 3. Stereoscopy of the UV/condensation conditioned CF/PPS laminates with (a) no conditioning and obtained by (b) fast; (c) slow; and (d) in air cooling.

As it can be seen in Table 4, the ILSS values of the composites after the UV/condensation conditioning were reduced. The samples obtained by in air cooling were more affected ( 62\%), followed by slow $(\sim 44 \%)$ and fast $(\sim 22 \%)$ cooling. This result is in agreement with the values found for the Young's moduli and also the stereoscopy of the samples surfaces after UV/condensation conditioning, where the degradation was more severe for the composites with higher crystalline contents. Moreover, some previous studies also showed a reduction in the Young's modulus [29] and ILSS [31] after exposing PPS composites to UV radiation.

\section{Conclusions}

In the present study, the effect of hygrothermal, salt fog, and UV/ condensation conditioning on CF/PPS composites with different degrees of crystallinity was evaluated. The main conclusions drawn are summarized as follows:

- The hygrothermal conditioning showed to increase the crystallinity degree due to the high temperatures and water uptake. As a result, an increment in storage modulus was observed. Moreover, the water ingress and the changes in crystallinity and storage modulus were more pronounced for the samples with lower crystalline content. No significant variations were verified for the Young's modulus and ILSS.

- The exposure to salt fog affected mostly the composites with lower degree of crystallinity, leading to higher weight gain, drop in the storage and Young's moduli and an increase in the damping. As a consequence of the degraded fiber-matrix interface, no ILSS valid results were obtained. The $\mathrm{NaCl}$ migration in the composite and the higher weight gain probably contributed to the overall loss of mechanical strength.

- The UV/condensation conditioning caused an increase in the crystallinity degree of the composites with the least crystalline content by a process called chemi-crystallization. An increment in the storage modulus resulted from this variation. On the other hand, composites with higher crystallinity degree showed to be more vulnerable to the synergistic effects of UV radiation and moisture. As a consequence of the degradation, reduction in the glass transition temperature, Young's modulus and ILSS were observed.

- Overall, the crystallinity degree proved to influence the weatherability. While the high crystalline content acted as a barrier to reduce the water and saline solution ingress, it intensified the degradation by trapping the UV rays in the polymer for a longer period of time.

\section{Acknowledgements}

The authors would like to thank FAPESP (Process numbers 2012/ 12207-6 and 2016/07209-0), CNPq (Processes numbers 303287/ 2013-6 and 303224/2016-9), CAPES/PVNS and CAPES (Process number 12357-13-8) for the financial support. Acknowledgements also go to the 17th European Conference on Composite Materials (ECCM17).

\section{Appendix A. Supplementary data}

Supplementary data related to this article can be found at https://doi.org/10.1016/j.polymdegradstab.2018.03.008.

\section{References}

[1] K.B. Mahat, I. Alarifi, A. Alharbi, R. Asmatulu, Effects of UV light on mechanical properties of carbon fiber reinforced PPS thermoplastic composites, Macromol. Symp. 365 (2016) 157-168.

[2] A. Messana, A.G. Airale, A. Ferraris, L. Sisca, M. Carello, Correlation between thermo-mechanical properties and chemical composition of aged thermoplastic and thermosetting fiber reinforced plastic materials, Mater. Sci. Eng. Technol. 48 (2017) 447-455.

[3] D. Blond, B. Vieille, M. Gomina, L. Taleb, Correlation between physical properties, microstructure and thermo-mechanical behavior of PPS-based composites processed by stamping, J. Reinforc. Plast. Compos. 33 (17) (2014) 
1656-1668

[4] K.K. Kar, J.K. Pandey, S.K. Rana, Handbook of Polymer Nanocomposites: Processing, Performance and Application, Springer-Verlag Berlin Heidelberg 2014, https://doi.org/10.1007/978-3-642-45232-1.

[5] A. Zafar, F. Bertocco, J. Schjødt-Thomsen, J.C. Rauhe, Investigation of the long term effects of moisture on carbon fibre and epoxy matrix composites, Compos. Sci. Technol. 72 (2012) 656-666.

[6] V. Saponara, Environmental and chemical degradation of carbon/epoxy and structural adhesive for aerospace applications: fickian and anomalous diffusion, Arrhenius kinetics, Compos. Struct. 93 (2011) 2180-2195.

[7] Y. Hu, A.W. Lang, X. Li, S.R. Nutt, Hygrothermal aging effects on fatigue of glass fiber/polydicyclopentadiene composites, Polym. Degrad. Stabil. 110 (2014) 464-472.

[8] S. Eslami, A. Honarbakhsh-Raouf, S. Eslami, Effects of moisture absorption on degradation of E-glass fiber reinforced Vinyl Ester composite pipes and modelling of transient moisture diffusion using finite element analysis Corrosion Sci. 90 (2015) 168-175.

[9] X. Jiang, H. Kolstein, F.S.K. Bijlaard, Moisture diffusion in glass-fiber-reinforced polymer composite bridge under hot/wet environment, Compos. B Eng. 45 (2013) 407-416.

[10] S. Sethi, B.C. Ray, Environmental effects on fibre reinforced polymeric composites: evolving reasons and remarks on interfacial strength and stability, Adv. Colloid Interface Sci. 217 (2015) 43-67.

[11] E. Faguaga, C.J. Pérez, N. Villarreal, E.S. Rodriguez, V. Alvarez, Effect of water absorption on the dynamic mechanical properties of composites used for windmill blades, Mater. Des. 36 (2012) 609-616.

[12] S. Alessi, G. Pitarresi, G. Spadaro, Effect of hygdrothermal ageing on the thermal and delamination fracture behaviour of CFRP composites, Compos. B Eng. 67 (2014) 145-153.

[13] D.E. Mouzakis, H. Zoga, C. Galiotis, Accelerated environmental ageing study of polyester/glass fiber reinforced composites (GFRPCs), Compos. B Eng. 39 (2008) 467-475.

[14] R. Šturm, R. Grimberg, A. Savin, J. Grum, Destructive and nondestructive evaluations of the effect of moisture absorption on the mechanical properties of polyester-based composites, Compos. B Eng. 71 (2015) 10-16.

[15] O.A.Z. Errajhi, J.R.F. Osborne, M.O.W. Richardson, H.N. Dhakal, Water absorption characteristics of aluminised E-glass fibre reinforced unsaturated polyester composites, Compos. Struct. 71 (2005) 333-336.

[16] I. Kafodya, G. Xian, H. Li, Durability study of pultruded CFRP plates immersed in water and seawater under sustained bending: water uptake and effects on the mechanical properties, Compos. B Eng. 70 (2015) 138-148.

[17] G.C. Papanicolaou, D. Karagiannis, D.A. Bofilios, J.H. Lochem, C. Henriksen, H.H. Lund, Impact strength of recycled thermoplastic composites subjected to corrosive environment, Polym. Compos. 29 (9) (2008) 1026-1035.

[18] T. Kawaguchi, H. Nishimura, F. Miwa, K. Ito, T. Kuriyama, I. Narisawa, Hot water resistance of glass fiber reinforced thermoplastics, Weathering Plastic (1999) 99-104.

[19] M. Deroiné, A. Duigou, Y.-M. Corre, P.-Y. Gac, P. Davies, G. César, S. Bruzaud, Accelerated ageing of polylactide in aqueous environments: comparative study between distilled water and seawater, Polym. Degrad. Stabil. 108 (2014) $319-329$
[20] V.M. Karbhari, K. Ghosh, Comparative durability evaluation of ambient temperature cured externally bonded CFRP and GFRP composite systems for repair of bridges, Compos. Part A-Appl. S 40 (9) (2009) 1353-1363.

[21] P. Davies, F. Rannou, W.J. Cantwell, F. Pomiès, L.A. Carlsson, Durability of composite materials in a marine environment, in: Proceedings of ICCM/9 Conference. Madrid, Jul, 1993, pp. 308-315.

[22] F. Pomiès, L.A. Carlsson, J.W. Gillespie Jr., in: R.H. Martin (Ed.), Marine environmental Effects on Polymer Matrix Polymers. Composite Materials: Fatigue and Fracture - Fifth Volume, ASTM STP 1230, American Society for Testing Materials, Philadelphia, 1995, pp. 283-303.

[23] A.P. Costa, E.C. Botelho, L.C. Pardini, Efeito da degradacao ambiental nas propriedades de cisalhamento de compositos PPS/Fibra de carbono, Polimeros 21 (3) (2011) 161-167.

[24] T.-C. Nguyen, Y. Bai, X.-L. Zhao, R. Al-Mahaidi, Effects of ultraviolet radiation and associated elevated temperature on mechanical performance of steel/ CFRP double strap joints, Compos. Struct. 94 (2012) 3563-3573.

[25] H. Gu, Degradation of glass fibre/polyester composites after ultraviolet radiation, Mater. Des. 29 (2008) 1476-1479.

[26] A. Afshar, M. Alkhader, C.S. Korach, F.-P. Chiang, Effect of long-term exposure to marine environments on the flexural properties of carbon fiber vinylester composites, Compos. Struct. 126 (2015) 72-77.

[27] A. Ghasemi-Kahrizsangi, H. Shariatpanahi, J. Neshati, E. Akbarinezhad, Degradation of modified carbon black/epoxy nanocomposite coatings under ultraviolet exposure, Appl. Surf. Sci. 353 (2015) 530-539.

[28] V.S. Chevali, D.R. Dean, G.M. Janowski, Effect of environmental weathering on flexural creep behavior of long fiber-reinforced thermoplastic composites, Polym. Degrad. Stabil. 95 (2010) 2628-2640.

[29] F. Awaja, M.-T. Nguyen, S. Zhang, B. Arhatari, The investigation of inner structural damage of UV and heat degraded polymer composites using X-ray micro CT, Compos. Part A-Appl. S 42 (2011) 408-418.

[30] T. Sinmazçelik, Natural weathering effects on the mechanical and surface properties of polyphenylene sulphide (PPS) composites, Mater. Des. 27 (2006) $270-277$.

[31] M.C.M. Faria, F.C. Appezzato, M.L. Costa, P.C. Oliveira, E.C. Botelho, The effect of the ocean water immersion and UV ageing on the dynamic mechanical properties of the PPS/glass fiber composites, J. Reinforc. Plast. Compos. 30 (20) (2011) 1729-1737.

[32] A.P. Costa, E.C. Botelho, L.C. Pardini, Influence of environmental conditioning on the shear behavior of poly(phenylene sulfide)/glass fiber composites, J. Appl. Polym. Sci. 118 (2010) 180-187.

[33] B. Vieille, J. Aucher, L Taleb, Influence of temperature on the behavior of carbon fiber fabrics reinforced PPS laminates, Mater. Sci. Eng. A-Struct. 517 (2009) 51-60

[34] I.H. Craig, J.R. White, P.C. Kin, Crystallization and chemi-crystallization of recycled photo-degraded polypropylene, Polymer 46 (2005) 505-512.

[35] N.L. Batista, P. Olivier, G. Bernhart, M.C. Rezende, E.C. Botelho, Correlation between degree of crystallinity, morphology and mechanical properties of PPS/carbon fiber laminates, Mater. Res. 19 (2016) 195-201.

[36] U.W. Gedde, Polymer Physics, Springer Netherlands, 1999, https://doi.org/ 10.1007/978-94-011-0543-9. 